\title{
BENJAMÍN JARNÉS Y EL DOCTOR SANSÓN CARRASCO: ASPECTOS CERVANTINOS DE LA TEORÍA DEL ZUMBEL
}

\author{
[...] cogollo y cifra del sentido \\ Miguel de Unamuno \\ Vida de Don Quijote y Sancho.
}

\author{
Pablo Muñoz Covarrubias \\ Universidad Autónoma Metropolitana-Iztapalapa \\ juanpablomunozcovarrubias@gmail.com
}

\begin{abstract}
RESUMEN / ABSTRACT
El propósito de este artículo es estudiar una de las obras de ficción más importantes del escritor español Benjamín Jarnés. Teoría del zumbel (1930) puede ser leída como un manifiesto y también como una novela. En todo caso, es un buen ejemplo del arte vanguardista. A pesar de que pueda resultar fácil describir el estilo de Jarnés como moderno y como experimental, este libro en particular pertenece a la tradición de la novela inventada por Cervantes. Sansón Carrasco es uno de los personajes centrales de Teoría del zumbel y llega a simbolizar la razón de acuerdo con Jarnés. El presente artículo describe la forma en que este personaje en particular es incorporado por el escritor en su novela.
\end{abstract}

Palabras Clave: Jarnés, Teoría del Zumbel, Cervantes, vanguardia, Sansón Carrasco.

The purpose of this article is to focus in one of the most important pieces of fiction written by Spanish author Benjamín Jarnés. Teoría del zumbel (1930) can be read both as a manifesto and as a novel. In any case, it is a very good example of the Spanish Avant-Gard. Although there is no difficulty in recognizing Jarnés' style as modern and experimental, this book in particular also belongs to the tradition of the novel invented by Cervantes. Sansón Carrasco is one of the main characters in Teoría del zumbel. It symbolizes reason according to Jarnés. This article describes the way in which this particular character is incorporated by the writer into his novel.

KeYWords: Jarnés, teoría del Zumbel, Cervantes, avant-gard, Sansón Carrasco. 
La presencia de lo cervantino -y de lo quijotesco- en la obra de Benjamín Jarnés es casi evidente. Aparecen en sus textos, a veces de forma ya concentrada o ya dispersa, brillantes referencias y elementos pertenecientes al mundo del Quijote. Jarnés escribió hacia el final de su vida una interesante biografía, a veces desdeñada por los investigadores por considerarla un trabajo de encargo, en que resume algunas de sus ideas centrales en torno al autor de la novela más famosa de todos los tiempos: Cervantes (1944). También Jarnés escribió un par de textos -que acaso sean cuentos o relatos o bien otra cosa- en que el personaje central es la enamoradiza y enigmática Altisidora. Cardenio es una breve obra de teatro de 1934 que se editó en México, como opúsculo, en 1940. Como puede ya preverse, Jarnés se interesó sobre todo por los personajes -en apariencia- secundarios del Quijote: Altisidora, Cardenio y Sansón Carrasco. El presente trabajo es una investigación en torno a este último personaje en la obra de Jarnés, particularmente, como presencia en una brillante novela suya. Antes de ahondar en la cuestión, creo que vale la pena adelantar el hecho de que cada uno de estos personajes cervantinos adquiere un peso simbólico, y completamente personal, en el universo literario de Jarnés. Cardenio será la representación de la soledad del poeta. Altisidora, por su parte, es la encarnación casi mítica de la figura femenina cuando se enamora. Y por último: Sansón Carrasco, en la Teoría del zumbel, es una alegoría de la razón ${ }^{1}$. Como bien lo ha podido demostrar Santiago Alfonso López Navia en un amplio estudio en torno de las muchas recreaciones del personaje de Don Quijote, son muchísimos los textos -y también los ámbitos artísticos- en que se han reescrito y reinventado las peripecias del andante caballero. De acuerdo con López Navia, pareciera que continuamente se le negara a Don Quijote la paz y el descanso de su sepultura eterna, pues tenemos

\footnotetext{
El interés por Cervantes y por Don Quijote se manifiesta prácticamente en gran parte de la obra literaria de Jarnés. En 1936, en Citas de ensueños (figuras del cinema), podemos hallar "La gran aventura quijotesca", un muy interesante comentario acerca de Don Quijote (1933), película dirigida por Georg Wilhelm Pabst. Jarnés piensa que esta película es "[...] un excelente poema dramático al cual se subordinan las demás artes -plásticas, musicales, literarias- para componer la más original rapsodia española de estos tiempos" (108). Acerca del final, destaca Jarnés la decisión de Pabst de no representar la muerte del héroe con la tranquilidad escogida por Cervantes. En cambio, acabaría la existencia del hidalgo con un ambiente muy similar al de un auto de fe: "[...] este film -llevado a cabo con pericia de gran técnico y de gran artista- posee la virtud de ir graduando los efectos dramáticos, de tal modo que se reserva para el final [...] una patética hoguera, la del escrutinio" (110). También es curioso recordar lo que apuntó José-Carlos Mainer en su Moradores de Sansueña acerca del inacabado proyecto de Jarnés que habría llevado como título el de Desierto profanado, texto en apariencia de 1946 en que haría acto de presencia Aldonza Lorenzo (143-145).
} 
un "[...] Don Quijote a quien nadie quiere dejar descansar en paz a pesar de haber vivido una existencia ya sobradamente asendereada en el mundo literario, incómodo y a veces hostil [...]" (50). En cierta medida, el texto que aquí se analizará centralmente es consecuencia de esa misma intención de hacer resucitar el mundo de la novela cervantina, pero con una impronta teñida por el pensamiento de la época en que le tocó vivir y escribir a Jarnés.

De entre las muchas novelas escritas por Benjamín Jarnés, Teoría del zumbel de 1930 es sin duda una de las mejores por su propuesta literaria. De hecho, se publica en la época en que Jarnés logra el general consenso de la crítica en torno a su talento como narrador y como estilista. Es un libro complejo y en que se rompen, con absoluta conciencia, las convenciones centrales del género novelístico en su vertiente más tradicional. Para comenzar, es necesario decir que no deja de ser deslumbrante la presencia en Teoría del zumbel, sobre todo, de dos personajes extraordinarios por su naturaleza y por las funciones que cumplen en el relato: el novelista que, en teoría, se encuentra escribiendo la novela que nosotros, a su vez, estaríamos leyendo; y también, y sobre todo, la del muy famoso y archiconocido Sansón Carrasco, creatura familiar para los lectores de Don Quijote.

Acerca del supuesto y ficticio novelista de Teoría del zumbel, es válido decir que su presencia nos lleva de inmediato hacia los territorios de la metaliteratura, pues se trata de un personaje que pretendidamente desborda los ámbitos tradicionales de la ficción y que estaría construyendo el texto que nosotros tendríamos. En este sentido, el recurso es de clara estirpe cervantina; recordemos el hecho de que el narrador de Don Quijote también se convierte en una presencia latente y viva en la novela de Cervantes y que somos testigos, como lectores de su texto, de su supuesto proceso de escritura y de las interrupciones y peripecias que se suscitan a su vez por no tener el manuscrito completo de Cide Hamete Benengeli. Resultará conveniente indicar aquí algunas de las características del "novelista" de Teoría del zumbel para poder comprender su papel específico: es un personaje que se concibe, más que como el auténtico creador del libro, como un "espectador puro", tal y como se asienta al finalizar el capítulo primero de la novela: un llano y simple cronista de aquello que contempla (un imitador, un practicante de la mímesis, alguien que se inspira directamente en la realidad). Por su parte, el narrador del Quijote se presenta a sí mismo como un hombre que, en todo caso, gracias a la buena fortuna y a la curiosidad, halló los documentos complementarios en un mercado; y solo entonces encargó su traducción, del árabe al español, de tal modo que pudo así continuar con la narración de los hechos quijotescos. De otra manera, según se deduce, nosotros no habríamos llegado a conocer las aventuras del hidalgo. Lo que ambos textos cuestionan 
con gran originalidad - elemento notable tanto en el texto cervantino como en la novela vanguardista- es la figura del autor. Hay que añadir, por cierto, una influencia más en lo que a esto respecta para el análisis de la novela de Jarnés: la huella unamuniana en la construcción de una frontera borrosa entre la realidad y la ficción.

Sin embargo, lo más cervantino de Teoría del zumbel de Jarnés no es principalmente este repertorio de elementos metaliterarios y ese sofisticado juego con el narrador en tanto que personaje de la novela; es probable que lo más llamativo sea en todo caso la recuperación -y la simultánea simbolizaciónde Sansón Carrasco, así como también la estructura general del libro que se deriva, en parte, de su inclusión. Antes de comentar la función y la gran relevancia de este personaje aun como generador de la estructura del libro, quisiera recoger algunos de los sugerentes planteamientos con que abre la novela. Me refiero a las curiosas anotaciones de esa especie de prólogo $-\mathrm{O}$ de larga reflexión- que el autor tituló como "Bajo el signo de cáncer (nota preliminar)". El comentario de las páginas preliminares me servirá para explicar tangencialmente la función de Sansón Carrasco en la novela de Jarnés - los motivos por los cuales aparece en la historia como un juez o como una presencia que simboliza la razón-. En su indispensable estudio acerca de la obra de Jarnés (Arte y vida en la obra de Benjamín Jarnés), la investigadora Eugenia Zulueta incluso llegó a proponer que este personaje encarnaría novelísticamente algunos de los conceptos expuestos en el prólogo.

Resulta claro para cualquier lector, tras recorrer las páginas que enmarcan la novela, que Jarnés conocía muy bien por aquellos años las teorías psicoanalíticas en boga y que había leído con gran provecho a Jung: varios de los párrafos del texto son, en realidad, una glosa de las ideas del psicólogo en torno a "[...] el campo de las reminiscencias personales y el campo de la 'historia general humana'" (Jarnés, Teoría del zumbel 11). Por supuesto, lo que resulta fundamental es la exposición en torno a la manera en que el arte recoge y replantea lo que se conoce y también lo que se intuye, lo que se sabe y también lo que se sueña y se ignora. Por lo que se propugna en estas notas prologales -y sin duda programáticas- es por una suerte de equilibrio entre las fuerzas que animan y orientan el quehacer del hombre en tanto que creador: "Ninguna máquina tan necesitada de ese equilibrio como la sutil máquina del artista. Una válvula de escape no puede producir la obra bella, ni un obstinado bruñido de cada pieza. Sentir, cuando se trata de razonar, es malo. Razonar cuando se trata de ver, es peor" (16). A diferencia de los surrealistas, el escritor no aboga aquí por el uso del inconsciente como estímulo para la escritura; de hecho, detectó Jarnés en los artistas del surrealismo un supuesto defecto mayúsculo: la ausencia de un estilo propio en cada caso. 
Todo "ismo" -según leemos en el prólogo- se convierte en un "callejón sin salida": “Eclecticismo? No. Integralismo. Aunque mejor sería prescindir también de este y de todos los-siempre insoportables-ismos. El sueño está muy bien, pero también lo está el ensueño. Y, con el sueño y el ensueño, con las encrucijadas y las destrenzadas nubes, la vigilia" (30). Es decir, el texto literario debería convertirse en un espacio abierto en que pudieran convivir, armónicamente, todos los ámbitos, sin desechar ni menoscabar ninguno de ellos. Es pues coherente el proyecto literario de Teoría del zumbel con tal propuesta: erigirse como un libro que demuestre, y que ejemplifique, esa síntesis, ese espíritu que sirva para reparar la experiencia humana escindida hasta ahora por la necesidad de preferir alguna de las vertientes señaladas (sueño o vigilia). Al rastrear la vertiente surrealista de Teoría del Zumbel, David Conte se hace la siguiente pregunta: "[...] esta visión del 'hombre integral' ¿no es acaso equivalente al sueño surrealista por reconciliar los mundos oníricos con la plenitud de la vigilia?" (91). Todos los ismos -de acuerdo con el señalamiento de Jarnés- atentarían en contra de dicha posibilidad integradora. De igual manera, podría parecer que existiese una oposición entre vida y literatura, entre lo vital y lo que ocurre intelectualmente al sumirse en las páginas de un libro. Inteligentemente, José E. Serrano Asenjo explica cómo se resuelve esta otra tensión u oposición: "[...] en última instancia lo que hace [Jarnés] no es tanto remitir la vida a la literatura, como proporcionar unas indicaciones valiosísimas para que la novela pueda servir en el acecho de lo vital, o lo que es lo mismo, para que las ficciones literarias puedan enfrentarse a la realidad compleja, única, mutable, mágica que es la vida" (45).

Teoría del zumbel pretende pues ser un espacio textual en que se armonicen los diversos ámbitos de la experiencia del hombre. Solo de esta manera todo lo humano quedará en verdad reflejado en -y por- el libro. Como puede derivarse, Teoría del zumbel es mucho más que una novela: es la materialización, desde el arte y desde la literatura, de lo que debería ser la vida humana con toda su complejidad y en su diversas facetas; en este sentido, algo hay de utópico y de ingenuo en el proyecto jarnesiano. Como muy bien lo vio Pedro Salinas al analizar la forma en que la realidad y la poesía conviven intensa y armónicamente en la obra del autor, "en todas las novelas de Jarnés apreciamos esa vaguedad, esa composición que no responde nunca a las asociaciones rigurosamente lógicas del mundo externo, ese aire de juego mental, que le dan su tono inconfundiblemente poético. Lo real en sus obras aparecerá siempre precisamente con ciertas inquietantes y estremecedoras sospechas de irrealidad" (316). Como novela sin duda vanguardista, Teoría del zumbel propicia la imposibilidad de asentar, con claridad, su propia trama en cada uno de sus pasajes; en todo caso, la historia adolece y goza de una 
buscada y rebuscada vaguedad. De esta manera, se construye un mundo con una lógica propia, así se reflejan los principios estéticos antes mencionados: una realidad entredicha que colinda, permanentemente, con lo irreal, donde se mezclan y se funden. En palabras de Jarnés, y todavía en el prólogo de Teoría del zumbel:

No se trata de técnicas; se trata del conocimiento integral del hombre, de la revelación de esta sabiduría de hombre por una personalidad robusta. No se trata de maneras y de modos, sino de ciencia del ver y de expresar libremente lo visto. Sin excluir zona alguna del blanco, parcela y estado alguno del hombre; vigilia y ensueño, razón y pasión, serenidad e inquietud enfocada hacia el futuro, reposo de lo enraizado, capacidad mística para crearse volutas de nube (26).

En esta misma medida, privilegiar lo puramente instintivo o lo racional sería erróneo. En Teoría del zumbel vamos a encontrar la representación práctica y literaria de dicha dialéctica. La figura de Sansón Carrasco es el remedio en contra de lo irracional y lo instintivo que subyace en el "amor loco" y en la pasión desenfrenada. Lo que se narra en Teoría del zumbel es una historia de amor que se ha contado cientos de veces, que se nutre además de lugares comunes y de tópicos manidos, pero que se construye, se deconstruye y destruye, al mismo tiempo, página tras página y sin descanso ni tregua. De hecho, el narrador indicará que la historia que se va a contar en el libro es algo incipiente, un mero "brote novelesco", las primeras instancias y los primeros momentos del amor entre Blanca y Saulo, un libro que aspiró a ser "novela blanca", pero que acaba -para fortuna nuestra-por descarrilarse. La "novela blanca", para serlo, debe adecuarse y obedecer las expectativas del lector más conformista, y carecer de elementos que permitan detectar algo parecido a un pensamiento original: un texto sin riesgo ni apuesta literaria. Nada más alejado de la poesía, por tanto, que una "novela blanca". Teoría del zumbel sería, como verdadero texto de vanguardia, lo opuesto: un libro que continuamente resulta incómodo para su lector. En sus páginas, leemos y leemos y seguimos un proceso que representa el alejamiento decidido de tales convenciones, de la pereza creativa. El concepto de "novela blanca" tiene que ver, pues, con el supuesto tipo de texto que concretamente se negó a aparecer en las páginas de Teoría del zumbel a pesar del tipo de personajes y de la trama, en apariencia, romántica y estereotipada.

En el primer capítulo de Teoría del zumbel, cervantinamente llamado "El caballero de los espejos", conoceremos a Blanca. Su nombre no deja de ser altamente significativo y desde luego simbólico: una mujer virginal e inocente cuyo romance será sugerido, armado y consensuado por las figuras de 
autoridad que la rodean, entre otros, el padre Valdivia ("la historia de Blanca es la historia de una categoría", escribirá el narrador, como si fuese ella un arquetipo y no una mujer real de carne y hueso). El pretendiente de Blanca es Saulo, el joven e irresponsable dueño de la Banca Bermúdez. Saulo es un hombre rico y libertino, un producto inmediato y directo del capitalismo desenfrenado, una actualización donjuanesca ${ }^{2}$. El matrimonio de Blanca con Saulo tendría la virtud, de acuerdo con quienes así lo piensan en el libro, de permitir que el personaje masculino rectifique y abandone su vida licenciosa (“‘Saulo era una presa de Satán!”). Además, como lo expresa el sacerdote Valdivia en un diálogo con el supuesto autor de la ficción, con el pretendido novelista, el vínculo entre estos dos personajes serviría, de paso, para que el autor, para que el novelista, pueda escribir por fin una "magnífica novela". Siguiendo esta llamativa interpretación, quedaría entonces la anécdota predestinada para el ejercicio de la escritura y la construcción inmediata del texto novelístico. La historia, tal como aquí se plantea, resultaría además ideal para la escritura de una "novela blanca".

Por su parte, Saulo piensa en beneficiar a Blanca gracias al enlace matrimonial: "[...] quiero rectificar su vida, esa vida absurda que suele llamarse de piedad. Quiero hacer de ella una mujer actual, arrancarla del medievalismo en que vegeta" (59). No es por amor, en realidad, que Saulo acepte casarse, por lo visto, con Blanca; es porque al casarse con ella logrará modernizarla, hacer que abandone su estado cándido y virginal, y que se instale en el mundo contemporáneo. El novelista, al escuchar el extraño plan de Saulo, no podrá refrenarse e importantemente exclamará: “ $i Q u e ́$ extraño caso! ¡Un quijotismo recíproco!” (59). Precisamente se trata, como lo dice el novelista, de un "quijotismo recíproco" puesto que ambos personajes han dejado de aceptar la realidad tal como esta se presenta; quieren, a la manera del Caballero de la Triste Figura, incidir en el mundo de forma directa y heroica, cambiar abruptamente el statu quo, luchar contra la realidad y sus

Al leer Teoría del zumbel, resulta muy difícil no pensar en El hijo del millonario, "novela falsa" creada por Ramón Gómez de la Serna. En este texto, el creador de las greguerías parodia, por medio de su texto, la novela norteamericana. El protagonista, como lo recordarán los lectores de esta pequeña novela, es el hijo de un exitoso capitalista. Esta condición le otorga al personaje la capacidad de ser salvajemente libre en un mundo maquinizado y orientado hacia la producción y hacia la desigualdad social. David Karvaler -así se llama el personaje de El hijo del millonario-, al igual que el protagonista de Teoría del zumbel, vive una vida vertiginosa y con códigos morales que se derivan de su capacidad de poseer una gran fortuna. La propuesta de Gómez de la Serna, sin embargo, llega todavía más lejos puesto que David Karvaler es un asesino y, entre sus planes se encuentra la intención de hacer explotar la fábrica en que se encuentran sus trabajadores. 
características presentes. Toda estrategia que incluya tal propósito -modificar la realidad- es descrita, en el mundo moderno de la Teoría del zumbel, con un concepto de raigambre antigua: la palabra o el concepto quijotismo nos remite al mundo, solo en apariencia lejano, del Caballero de la Triste Figura ${ }^{3}$. Posteriormente, Saulo expresará su noble intención de imprimir en la vida de Blanca cierta agitación, una "risueña aceleración". Al confesar su plan, recibirá una respuesta muy similar a la anterior: "iQuijote del dinamismo!" (65). Y también se menciona en el texto que ha de sufrir una conversión: "Dejarás de ser Saulo el que guarda la ropa, como el otro, para convertirte en el frenético Pablo, en Don Quijote del matrimonio ideal. ¡Hombre feliz! ¡Hombre de dos destinos! ¡Que el empalme no rompa en ti la corriente ideal!” (66). Si bien resultaría poco viable determinar, gracias al análisis de sus características, un paralelismo entre Saulo y Alonso Quijano, es notable que ambos, gracias al comienzo de sus aventuras, modifiquen sus nombres: Saulo-Pablo y Alonso Quijano-Don Quijote; aunque, como veremos más adelante, Saulo no podrá en realidad, a la manera del hidalgo, "convertirse en caballero andante". Así como don Quijote, y por supuesto lo quijotesco, se relacionan con ese deseo de modificar el estado de las cosas y de las personas y del mundo, con ese mismo ímpetu idealista, con esa misma voluntad, por principio de cuentas, se ha de conducir Saulo al aceptar el matrimonio con Blanca. Es su misión, tal como se menciona, regalar a la mujer la velocidad y el dinamismo del "mundo actual". Prácticamente, la concepción del amor que aquí se plantea es una derivación del credo vanguardista en su vertiente futurista.

Ahora bien, como un elemento que intenta refrenar esa impetuosa forma de proceder de los personajes ya mencionados -quienes abrupta y también frívolamente se han entregado al amor y al matrimonio-, aparecerá el bachiller de la novela cervantina por excelencia:

Acerca del concepto de quijotismo, existe un artículo de Jesús Ruiz Fernández incluido en la bibliografía de este trabajo-cuya lectura esclarece los alcances del término desde una óptica filosófica y con muchas referencias a la cuestión desde los ámbitos de España y sus intelectuales y escritores. Claramente, se trata de una noción que ha ido variando a lo largo del tiempo y con el paso de los siglos. Ruiz Fernández, por su parte, propone quedarse casi al comienzo del artículo con la acepción popular y acaso más general y esclarecedora: "hacerse ilusiones sobre las cosas". En el siglo XVIII, como lo ha demostrado Francisco Aguilar Piñal, el concepto tuvo que ver con "abatir los residuos barrocos de la vida y de las costumbres" (210) en la medida en que Don Quijote logró desterrar la novela de caballería. Durante el siglo XIX, es imposible no relacionar la palabra con el credo romántico alemán: el quijotismo como sinónimo de las conductas rebeldes e idealistas. Durante el siglo XX, se recibió, se amplió y se corrigió también tal planteamiento. Es muy probable que el quijotismo de Jarnés se nutra de dicha concepción romántica y que se apropie de ella desde los terrenos de la ficción. 
He aquí al doctor Carrasco. Los tres siglos le han cambiado bastante. Se doctoró, ahuecó algo la voz, cambió su rocín por un Ford... El caballo le idealizaba un poco, y el ex bachiller, enemigo de todo penacho, de toda prolongación inconcreta, asesinó también su propia estampa de gallardo jinete.

Este predicador sempiterno de la "vuelta a la realidad metodizada", inquisidor pertinaz del alma aventurera, asoma en toda vida que comienza a perder su equilibrio.

Por eso aparece aquí. Aunque a veces huye de los primeros términos y se refugia en la trastienda de la acción. El doctor Carrasco no pierde una escena. Suele disfrazarse; utiliza infinitas máscaras. Unas veces será el padre Valdivia, otras la solterona Julia, otras el amigo que "quiere bien" al presunto aventurero...

Hoy, en esta novela de Saulo, prefiere tomar parte sin disfraz alguno. Acaba de salir de la ciudad y viene al encuentro de su amigo. Sin gran velocidad, porque toda cautela es poca para cruzar esos caminos tan en rúbrica de Iturzaeta, llenos de atrevidas curvas.

Carrasco averiguó que Saulo iba a emprender una nueva existencia. Que Blanca y Saulo pretendían armonizar paralelamente sus vidas... ¡Blanca, sin fortuna, cursi doncella que borda tras los cristales en una capital de provincia, hija de un funcionario obscuro! ¿Diana cazadora de dotes? ¿Qué tino para tender su red a un financiero! Porque si Banca Bermúdez sufre hoy quebrantos, Blanca no puede todavía conocerlos.

Cuando los amigos supieron la noticia, la indignación fue unánime. ¡Saulo, que con un enlace bien estudiado podía recompensar su fortuna! Era urgente desviarlo de aquella quijotería, de aquel empeño de redimir doncellas arrinconadas; y para esos casos vino al mundo el doctor Carrasco, especialista en equilibrar las almas (73).

De esta manera, por medio de este personaje, se simboliza y se alegoriza lo racional, el poder de la razón y su oposición a toda suerte de aventuras. Blanca y Saulo - personajes quijotescos de acuerdo con la propuesta de Teoría del zumbel-se enfrentarán en contra de un personaje que habita las páginas de otra novela y que ha decidido intervenir sin haber sido invitado. Es un personaje que, sin embargo, se ha modernizado y reinventado: el bachiller Carrasco ya es doctor y ha cambiado su viejo caballo por un Ford, símbolo de la velocidad y del mundo contemporáneo. Se trata, como se asienta en la cita anterior, de un personaje que empieza por simplificar y por limpiar su propia figura al abandonar el caballo: "asesino también de su propia estampa de gallardo jinete". Mejor que nadie, Sansón Carrasco comprenderá el despropósito inherente en las intenciones del joven Saulo, pues no será la primera vez que se enfrente a un hombre enajenado por sus ideas y por sus 
locos sueños de grandeza; y tampoco será la última vez en que busque, lleno de prejuicios y de terribles y desagradables afanes inquisitoriales, refrenar los proyectos ajenos. No por nada ha de privilegiar, sobre todas las cosas, la "vuelta a la realidad metodizada", como buen hijo de Descartes: realidad y método. Pero su estrategia consistirá, básicamente, en dialogar, como si fuera una especie de moderno psicólogo ("confesor laico", diría Zulueta), con los protagonistas de la novela. Su combate será verbal y no a caballo ni con la espada por delante; de hecho, se resalta que no vestirá, como lo hizo en las páginas de Don Quijote, disfraz alguno. Su engatusamiento será por tanto de otra naturaleza y con otros recursos ${ }^{4}$. Así como el bachiller Sansón Carrasco se disfraza con las vestimentas que lo convertirán en Caballero de los Espejos para engañar a don Quijote, y traerlo de vuelta a su casa, al lado de su sobrina y su ama, el doctor Carrasco, en Teoría del zumbel, hará uso de otros medios y de otros recursos para impedir ese acto de quijotismo, la inminente boda de Blanca con Saulo: "El doctor Carrasco persigue a Bermúdez; lo encontrará; lo arrancará de esta vida insensata; le hará volver al pupitre, al teléfono, a la Bolsa, a la vida práctica, a la normalidad" (74). Esa normalidad de la cual habla Jarnés en Teoría del zumbel es una existencia en que se ausente la poesía, en que se incremente la burocracia o el conformismo burgués. Don Quijote, por su parte, pudo haberse quedado en su casa, al lado de su ama

$4 \quad$ Es prácticamente imposible no recordar aquí una interpretación semejante realizada por Unamuno, precisamente, de la figura del bachiller. En la segunda edición de su Vida de don Quijote y Sancho (1914), Unamuno va a incluir un artículo suyo -"El sepulcro de Don Quijote"-; en ese texto destacará el escritor el comportamiento inquisitorial de algunos de los personajes de la novela cervantina y fustigará esa manera de proceder, pues atentaría, según Unamuno, en contra del espíritu del famoso caballero: "Pues bien, sí; creo que se puede intentar la santa cruzada de ir a rescatar el sepulcro de don Quijote del poder de los bachilleres, curas, barberos, duques y canónigos que lo tienen ocupado. Creo que se puede intentar la santa cruzada de ir a rescatar el sepulcro del Caballero de la Locura del poder de los hidalgos de la Razón" (142). Cuando aparezca por primera vez Sansón Carrasco, en el capítulo tercero de la segunda parte, apuntará Unamuno: “[... ] bachiller por esta Salamanca de mis pecados, típico personaje que entra aquí en el tablado. Es este bachiller por Salamanca el hombre más representativo, después de nuestros dos héroes, que en la historia de estos juega papel; es el cogollo y cifra del sentido común, amigo de burlas y de regocijos, el cabecilla de los que traían y llevaban, dejándola uno para tomarla el otro, la vida del Ingenioso Hidalgo. Quedóse a comer con Don Quijote, y de refilón a burlarse de él para hacer honor a su mesa" (332). En su Vida de Don Quijote y Sancho, Unamuno no dejará de denunciar la "pequeñez de alma" del bachiller Sansón Carrasco y su necesidad de asegurar su propia fama por medio de la humillación de Don Quijote. A final de cuentas, según apunta el autor, Sansón Carrasco también habría adolecido de locura, pues es de locos el disfrazarse y caer en el juego quijotesco de la caballería andante; pero la locura del bachiller habría sido, según Unamuno, no del corazón, sino de la cabeza. 
y de su sobrina, cómoda y permanentemente instalado en su condición de hidalgo, sin experimentar las aventura y el mundo.

Cuando el doctor empiece a actuar en contra de ese acto de quijotismo, el novelista ha de reaparecer convenientemente para intentar reordenar y controlar las peripecias de su libro. Su cometido será impedir que ese "eterno asesino de aventuras" lleve a cabo con éxito su malintencionado plan; el novelista será presentado como una especie de divinidad que ha olvidado gobernar el mundo, en otras palabras, su propia creación textual. Frente a la oportuna intervención del novelista, no le quedará de otra al doctor Carrasco que empezar a planear un segundo intento, una segunda expedición, tal como sucede en la novela cervantina. Saulo será mientras tanto convocado por una multitud de mujeres, por la lascivia. Dije yo antes que la estructura de la Teoría del zumbel mantiene una deuda con la forma en que se organiza El Quijote en la medida en que se plantea una secuencia que se repite: la salida del caballero y la intervención del bachiller con resultados divergentes; algo de esto hay en la novela de Jarnés: dos intentos de Carrasco que buscarán detener la empresa quijotesca de Saulo. No deja de llamar la atención la manera en que el novelista enjuicia al personaje cuando este se bate, por fin, en retirada tras la primera envestida. Si bien busca compensar y refrenar los actos más ingenuos e idealistas, su razón y su entrometimiento servirán para condenarlo y para abjurar en contra de su presencia: "Lo dejamos ir, sin despedirnos de él. Es insufrible. Y para todos nosotros -héroes y cronistas- un mortal enemigo" (90). Sin embargo, el personaje ha de volver y ha de reiterar su esfuerzo. Esta defenestración será consecuencia de tratar de imponer una de las facetas de la vida -lo razonable- por encima de otro ámbito igualmente importante e imprescindible -lo espontáneo-. A esto se refería Zulueta al indicar que el doctor Carrasco representaría algunos de los conceptos del prólogo.

Hacia el final del libro, Blanca y Saulo tendrán un momento en que por fin convivirán a solas y -oblicuamente- han de consumar su amor (por la naturaleza escurridiza y elíptica del libro, por la vaguedad de la cual habló Salinas, en primera instancia, no será sencillo decidir si se trató o no de la realidad, de un sueño o de una ensoñación). Su unión definitiva y legal, sin embargo, será aplazada por un requerimiento del comité, aquel que regula cercanamente la Banca Bermúdez y también por la personalidad libertina e incontrolable de Saulo; se hace necesario que el personaje masculino se presente, ante la supuesta quiebra de la institución bancaria que él maneja, en una junta; después, será un inesperado accidente automovilístico la causa definitiva de su separación. El doctor Carrasco aprovechará lo ocurrido para informar a la mujer acerca de la ruina tanto física como económica de Saulo 
(es difícil no pensar, al menos por un momento, en Don Quijote -en Alonso Quijano- postrado en la cama: derrotado y falleciente). Después de dicha conmoción, el doctor Carrasco hablará con Blanca, quien a su vez no podrá explicar al personaje cervantino los matices extraordinarios de la experiencia carnal o sexual que ha vivido y que se confirmará gracias a su embarazo: "Ella no contesta. ¿Cómo explicar a Carrasco todo lo ocurrido? ¿No la ve ya hecha mujer, mujer recién nacida? Supo agotar todas las posibilidades de aquel programa de ardiente despedida... De despedida de Saulo y de una monótona doncellez" (185). El doctor Carrasco dejará de ser ahora un interlocutor adecuado, puesto que-azuzado por el deber ser-imposiblemente ha de entender ni de comprender la transformación gozada por Blanca, la sensualidad y su conversión en un ser por fin sexual y por tanto revitalizado. Sus poderes terapéuticos se acaban:

El doctor Carrasco, que no tolera recodos ni laberintos en la vida, que sólo se la explica conforme a un código, no puede recoger con sus manos asépticas, químicamente puras, esta vida sabrosamente impura que Saulo hizo estallar dentro de Blanca, al transformarla en mujer. La convertiría en algo tan impersonal como esta clínica, donde cada caso se incrusta en su precisa celda, cada variante en su página exacta. ¿Cómo va a aceptar Blanca esta futura etapa de insoportable equilibrio (189).

Es necesario aquí apuntar y recordar que el mundo narrativo de Jarnés es, como conjunto, un llamamiento a vivir la existencia con todas sus vertientes, experiencias y dimensiones, sin olvidar el amor y el erotismo y por supuesto la voluptuosidad; de igual forma, hay rastros en la cita de esta personal concepción, de ese afán de integrar lo diverso, lo cual ya es notable en novelas tan tempranas y también tan importantes como El convidado de papel (1928), obra oblicuamente autobiográfica. Un personaje químicamente puro, como el doctor Sansón Carrasco, representa una tozuda y clara incapacidad, casi congénita, para poder vivir con la plenitud requerida y recomendada; es todo aquello que rechaza y enjuicia, de forma práctica, el mundo literario de Benjamín Jarnés en su conjunto. Es lo aséptico, es quien vive no una vida, sino el obedecimiento de un código o de un conjunto de entristecidas normas.

El epílogo de la novela lleva por título el de "El caballero de la Blanca Luna". Si antes el Caballero de los Espejos salió derrotado en su intento por derrumbar los sueños quijotescos de Saulo, en esta sección final ha de salir, como en la segunda parte de la novela de Cervantes, triunfante ya que podrá por fin anular todo acto de idealismo o de quijotismo (por supuesto, como se ha visto, gracias a que la suerte y la fortuna se pusieron de su parte casi 
en el último momento del relato, por el accidente de Saulo). El novelista es, al inicio del epílogo, fuertemente regañado por su papel casi secundario en el diseño de la trama. Por medio de una charla con Paulina, una de las tantas amantes de Saulo, el novelista se enterará del triste destino de Blanca y de su situación final, un episodio que en definitiva no fue diseñado y que abruptamente ha surgido en su "novela blanca":

-Oye, Paulina, ¿conoces a estos dos?

-Sí. Son Blanca y Carrasco. Aquellos viajes a la clínica acabaron por dar este fruto. ¿No lo sabías?

-No. ¡Qué sorpresa!

-iQué desidia! ¿Cómo tienes abandonados así a tus personajes? Eres un novelista absurdo.

$-i$ Yo?

-Se te casan, se te mueren... y tú sin enterarte de nada. ¡Pobres lectores!

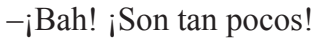

-Cada día serán menos si continúas escamoteándoles anécdotas. Debiste seguir paso a paso la vida de Blanca, sus amores con el doctor, y no andar persiguiendo sombras.

-iQuién iba a pensar!

- ¿Tampoco sabes que Blanca dio a luz? ¿Que el niño es de Saulo? ¿Que nació tres meses antes de la boda? ¿Que Carrasco lo perdonó todo, porque Blanca maternal estaba irresistible, mucho más linda que Blanca virginal y cursi?

-Eso no estaba en mi plan de novela blanca (244).

Sorprendentemente, al final del texto novelístico, seremos testigos de una extraña relación, rara por imprevista: la que ha surgido entre Blanca y Sansón Carrasco; de forma simultánea, también el novelista será sorprendido por esta improbable resolución de su texto. No deja de ser interesante que Sansón Carrasco termine, pero solo en apariencia, enamorado de Blanca. El pecado mayor del novelista ha sido su desidia, el hecho de que haya dejado de construir y de decidir los hechos centrales de su "novela blanca" -sus personajes se encargarán de pagar su indiferencia, su escamoteo-. En tanto que esto haya ocurrido, Sansón Carrasco habrá aprovechado tal desentendimiento a su favor. Al igual que en la segunda parte de Don Quijote, el bachiller -ahora doctor- ha logrado su cometido en la Teoría del zumbel: "Carrasco, el caballero de la Blanca Luna, ha ganado hoy la batalla; consiguió arrastrar al héroe hacia la serena paz; pero recuerda -dolorido- aquellas hazañas en que él no tomó parte, la vida anterior de Blanca, fecundada por Saulo" (247). Sansón Carrasco, en el texto de Jarnés, se ha apoderado de la figura femenina por excelencia, del personaje más cercano, en el libro, a la representación de 
Dulcinea del Toboso y a las figuras arquetípicas jarnesianas de lo femenino. A final de cuentas, este logro máximo es el resultado, como ya se ha visto, del descuido del novelista -o cronista- de Teoría del zumbel:

-¿Por qué me has abandonado? En cuanto te perdí de vista, mi vida recobró toda su monotonía, toda su domesticidad. Me entregué al doctor Carrasco, porque tú no viniste a defenderme.

-Era preciso, Blanca. Tu destino estaba ya cumplido.

-¿Cuál?

-El de hacer retoñar la vida de Saulo.

- ¿Y tan pronto quieres darme ya por vencida? ¿Vas a encerrarme para siempre? ¿Ni siquiera voy a poder lanzarme a ensayar una vida espontánea, entre árboles y pájaros, junto al río? Quisiera ser más libre. Carrasco es insoportable (250).

Si bien Carrasco - esa impecable alegoría de la razón, tal como la representa y construye Jarnés- se ha salido con la suya, es necesario subrayar que sigue siendo, como muy bien lo apunta Blanca, un ser monótono, sin pizca de romanticismo ni de entusiasmo, un hombre más bien gris. Aquello que se planteó desde el prólogo de la Teoría del zumbel resulta coherente con aquello que los personajes del libro terminan por representar, o por simbolizar, acaso mecánicamente. La triste imposición de lo racional -el éxito antiquijotesco de Sansón Carrasco- es una derrota de la vida en su vertiente más libre y dichosa y enriquecida; y es la culpa y el pecado, como ya se ha visto, de un novelista que olvidó diseñar su libro, su obra, que no supo cómo armonizar los distintos estímulos y los diversos matices de la experiencia humana con el equilibrio necesario o indispensable. Sansón Carrasco ha logrado entonces nulificar las peripecias -el amor y el deseo- en los territorios, otra vez, de la ficción.

Por último, debo agregar que la representación y la simbolización del bachiller en Teoría del zumbel, tan estrictamente riguroso y escrupuloso, puede ser la consecuencia de leer e interpretar las páginas del Quijote con un método que tiende a reducir, en gran medida, la rica complejidad de los personajes al alegorizarlos, al dejar de ver en ellos hombres y mujeres verdaderos, al imponer una estrategia de lectura que proviene de finales del siglo XIX y que, sin embargo, no desaparece del todo en las páginas de Jarnés ni siquiera hoy en día entre algunos críticos especializados. Es probable que Cervantes solo haya pensado en Carrasco, sobre todo, como un joven muy impetuoso, arrogante, burlón, socarrón, ingenioso y divertido; y como el encargado principal de retar al Caballero de la Triste Figura y de informar al hidalgo acerca de su condición de personaje literario en las páginas de la misma novela; no olvidemos que será el muchacho quien informe a Don 
Quijote acerca de la publicación de sus aventuras. La descripción de Sansón Carrasco en las páginas de Don Quijote es ilustrativa: "Era el bachiller, aunque se llamaba Sansón, no muy grande de cuerpo, aunque muy socarrón; de color macilenta, pero de muy bien entendimiento; tendría hasta veinticuatro años, carirredondo, de nariz chata y de boca grande, señales todas de ser de condición maliciosa y amigo de donaires y de burlas [...]" (II, 3). La configuración de Sansón Carrasco, según Cervantes y de acuerdo con sus rasgos físicos, es la de un hombre claramente sanguíneo; por tanto, su personalidad será la de un burlón y la de un verdadero travieso, no la de un hombre ciego y enajenado por la razón (inocentemente, en algún punto, Don Quijote incluso consideró convertirlo en su escudero). Como es bien sabido, será Sansón Carrasco quien, tras un intento fallido, y guiado por su espíritu chocarrero y socarrón y acaso algo vengativo, logre llevar al hidalgo hasta su hogar y convertirlo, para la tristeza de todos, menos de la sobrina y del ama, en Alonso Quijano el Bueno. La reinvención propuesta por Jarnés avanza por otros derroteros y como se ha visto por otros peculiares caminos.

\section{BIBLIOGRAFÍA}

Aguilar Piñal, Francisco. “Anverso y reverso del 'quijotismo' en el siglo XVIII español”. Anales de Literatura Española. 1982. 207-216.

Aub, Max. "Fantasmas de la novela y hoyanca de la generación del 31". Discurso de la novela española contemporánea. México: El Colegio de México, 1945. 81-96.

Cervantes, Miguel. Don Quijote de la Mancha. Ed. Francisco Rico. Madrid: Real Academia Española-Asociación de Academias de la Lengua Española-Santillana, 2004.

Conte, David. La voluntad de estilo. Madrid: Biblioteca Nueva, 2002.

Domínguez Lasierra, Juan. Benjamín Jarnés (1888-1949). Bibliografía. Zaragoza: Instituto Fernando el Católico, 2013.

Fuentes, Víctor. Benjamín Jarnés: biografía y metaficción. Zaragoza: Institución Fernando el Católico, 1989.

“Jarnés: metaficción y discurso estético-erótico". Jornadas jarnesianas. Zaragoza: Institución Fernando el Católico, 1989. 67-76.

Gómez de la Serna, Ramón. Seis novelas falsas: rusa, china, tártara, negra, alemana, americana. Madrid: Agencia Mundial de Librería, 1927.

Gullón, Ricardo. La novela lírica. Madrid: Cátedra, 1984.

Illie, Paul. "Benjamín Jarnés: Aspects of the Dehumanized Novel". Publications of the Modern Language Association of America 76 (1961): 247-253.

Jarnés, Benjamín. Paula y Paulita. Madrid: Revista de Occidente, 1929.

Teoría del zumbel. Madrid: Espasa-Calpe, 1930. 
Escenas junto a la muerte. Madrid: Espasa-Calpe, 1931.

Tántalo (farsa). Madrid: s.e., 1935.

"La gran aventura quijotesca". Cita de ensueños (figuras del cinema). Madrid:

Biblioteca del Grupo de Escritores Cinematográficos Independientes, 1936. 107-113.

El convidado de papel. Zaragoza: Nueva Biblioteca de Autores Aragoneses, 1979.

"Soledad de Cardenio. Soledades cervantinas" y "La desenvuelta Altisidora". Las

Españas. Historia de una revista del exilio (1943-1963). Pról. y ed. James Valender y

Gabriel Rojo Leyva. México: El Colegio de México, 1999. 511-514 y 683-692.

Cardenio. En La generación del 27 visita a Don Quijote. Pról. Jenaro Talens. Ed.

Jesús García Sánchez. Madrid: Visor, 2005. 409-421.

Cervantes. Pról. Domingo Ródenas de Moya. Madrid: Renacimiento, 2006.

López Navia, Santiago Alfonso. Inspiración y pretexto. Estudios sobre las recreaciones del Quijote. Madrid: Iberoamericana-Vervuert, 2008.

Mainer, José-Carlos. Moradores de Sansueña (Lecturas cervantinas de los exiliados republicanos de 1936). Valladolid: Junta de Castilla y León-Universidad de Valladolid-The Graduate Center, 2006.

Medina, Alberto. "Entre Don Quijote y Charlot: cine, sujeto y vanguardia en Benjamín Jarnés". eHumanista 3 (2014): 274-288.

Ortega y Gasset, José. La deshumanización del arte y otros ensayos de estética. Madrid: Austral, 1987.

Meditaciones del Quijote y otros ensayos. Madrid: Alianza, 2014.

Putman, Samuel. "Benjamín Jarnés y la deshumanización del arte”. Revista Hispánica Moderna 2 (1935-1936): 17-21.

Ródenas de Moya, Domingo. Los espejos del novelista: modernismo y autorreferencia en la novela vanguardista española. Barcelona: Península, 1998.

"Benjamín Jarnés, del vanguardista afable al escriba consumado". En Benjamín Jarnés. Elogio de la impureza. Invenciones e intervenciones. Madrid: Fundación Santander Central Hispano, 2007. IX-LXI.

Ruiz Fernández, Jesús. “El Quijote y el fenómeno del quijotismo”. Revista de Humanidades 20 (2013): 41-62.

Salinas, Pedro. "Benjamín Jarnés, novelista”. Obras completas II. Ensayos completos. Ed. Enric Bou y Andrés Soria Olmedo. Madrid: Cátedra, 2007. 315-317.

Serrano Asenjo, José. "Vida y literatura en Teoría del Zumbel de Benjamín Jarnés". Revista Hispánica Moderna 43 (1990): 42-48.

Unamuno, Miguel de. Vida de Don Quijote y Sancho. $6^{\text {a }}$ ed., Ed. Alberto Navarro. Madrid: Cátedra, 2005.

Zulueta, Emilia de. Arte y vida en la obra de Benjamín Jarnés. Madrid: Gredos, 1977. 